Revista Iberoamericana, Vol. LXXV, Núm. 227, Abril-Junio 2009, 445-458

\title{
REÍR CON EL MONSTRUO (REÍR CON AIRA)
}

\author{
POR \\ Ana B. Flores \\ Universidad Nacional de Córdoba
}

Al lector de César Aira, así haya leído dos o tres de los más de cuarenta relatos o "novelitas" de su autoría, ya no le sorprende que al comienzo, al medio o al final de las mismas aparezca un monstruo o se narre una monstruosidad. Hay gigantescos gusanos de seda que bajan por la montaña para destruir Mérida por una equivocación de la abeja encargada de tomar una muestra de Carlos Fuentes (y no de su corbata de seda) para clonarlo en El congreso de literatura (1999); hay gallinas atómicas en Embalse (1992); está el romance del Papa con una de las Mil gotas (2003) de óleo con que estuvo pintada La Gioconda cuando éstas salen a hacer su vida independiente del famoso retrato, etc. Reír con el monstruo, reír con las monstruosidades, y no sólo reírse de un monstruo, experiencias de "añiñamiento", ${ }^{1}$ son posiciones lectoras "efecto Aira" que torsionan las perspectivas habituales que consisten en preguntar quién es el monstruo, a quién una cultura construye como tal.

La pregunta que orienta esta propuesta es: ¿cómo es que las monstruosidades y los monstruos engendrados por mujeres jóvenes, las “chicas modernas” de Aira, dan risa? El "cómo" no se refiere sólo a los procedimientos sino sobre todo a la pregunta por la política de cierta literatura y cultura argentina, de la que Aira es un exponente mayor, no siempre reconocida como humorística por miedo a la confusión con la comicidad. Hay algunos intentos de nominación para dichos discursos, que tampoco pretenden abarcar una constelación de fronteras netas. María Moreno (2006) llama "populismo bright" a parte de esta producción, a propósito de Dalia Roseti (o Fernanda Laguna); o la que “expulsa al lector por irritación”, dice Tomás Abraham (2004) a propósito de la literatura de Aira, o la "comunidad inoperante de la literatura de izquierda”, dice Tabarovsky (2004), sobre la producción de Aira;

1 Dice Aira: “[...] todos mis libros son experimentos. Son pensados como tales, pero no se trata de experimentos hechos con la seriedad metódica de un científico sino con la seriedad ametódica de un sabio loco o de un niño que juega al químico y mezcla dos sustancias para ver qué pasa”. Se lee la herencia de Gombrowicz quien en el "Prólogo" para la primera edición castellana de Ferdydurke (1947) dice: “El supremo anhelo de Ferdydurke es encontrar la forma para la inmadurez”. 
Libertella, Fogwill, Lamborghini, Sánchez, Puig, Copi, Perlongher y unos pocos más. O la que produce la incomodidad que hace reír, dije en otro lugar, ${ }^{2}$ armando una constelación que suma a los derivados del Parakultural, el circuito "under" con las presentaciones de Urdapilleta, los programas televisivos "Cha, Cha, Cha", "Delikatesen”, "Todo por dos pesos”, y que reconoce como precursor (en sentido borgeano) a Macedonio Frenández. Tomo como punto de arranque, como ya se habrá sospechado, la novelita de César Aira Yo era una chica moderna, que curiosamente tiene el diseño de tapa hecho por Fernanda Laguna (y otras alusiones a Belleza y Felicidad, la editorial de dicha artista plástica) en su edición de Interzona.

Como hemos dicho más arriba, no contamos con categorías elaboradas para caracterizar este tipo de discursividades que nos ocupan pero podemos intentar hipotetizar sobre sus políticas. Una de las políticas de la comunidad inoperante (Tabarovsky) es intentar expulsar al lector, ${ }^{3}$ hacer de la literatura un mundo difícilmente habitable, pero no por críptico, inaccesible, al que se pueda llegar con mucho esfuerzo, sino por frustrar la credulidad, por bromear permanentemente con el lector hasta irritarlo. El famoso pacto de lectura se hace aquí presente pero por lo obsoleto. El poder de la literatura anterior -frente a la que esta es innovación pero no por ser lo último, sino por ser lo nuevo- era decirle al lector que la realidad no es como la presentan los medios masivos o el discurso social doxástico sino más compleja, más rica, oculta. El de la literatura aireana es decirle que no es de una forma ni de otra, sino que se puede jugar -es la literatura del "anenamiento"-a las mil posibilidades - con ecos macedonianos de la todoposibilidad-y ninguna, nunca se sabe, del sinsentido se pasa imperceptiblemente al no sentido. El poder de esta literatura es que para seguir en la montaña rusa de estos mundos inhabitables hay que estar en disponibilidad permanente. Lo cual es desestabilizar sin crear un nuevo paradigma; como el humor, da la respuesta no habitual a la ley, no para crear otra que no haría sino afirmarla como su contrario, sino para obstaculizar las creencias existentes, para que la eficacia esté bajo sospecha, con un desplazamiento de las peripecias, un final abrupto, un gag; literatura mala, tonta, es una imposibilidad, un otro del mundo, un malentendido, un puro gasto, un exceso. En ese sentido, es literatura monstruosa, no sólo "de monstruos", como intentaremos mostrar en este breve espacio.

Propongo entonces una presentación de algunos monstruos en la literatura aireana, un detenimiento en Yo era una chica moderna y luego reflexiones sobre la inscripción de estas apariciones del monstruo en la cultura argentina, en tanto innovación.

2 Parafraseando la expresión de Foucault, a propósito de "El idioma analítico de John Wilkins”, de Borges.

3 Siempre que hablemos de "lector" y de "lectura" lo hacemos en términos hipotéticos, de lector modelizado. 
En el marco para muchos expulsivo de la literatura de Aira aparecen los monstruos como síntomas; son los desambiguantes de que esta escritura quiere guerra al orden, a lo previsible. El monstruo ataca lo que queda de la confianza del lector acostumbrado al sistema literario serio, de academia, de mercado. Las posibilidades de emergencia de los monstruos en la dispositio son, previsiblemente, estas:

a) Si aparecen al final del texto producen un brusco viraje, una desviación abrupta del sistema de representación con que el lector venía colaborando, como en esa obrita de teatro o diálogo que es Madre e hijo (1993). En el desarrollo y desde las primeras líneas se presenta una primera ruptura de las regularidades de la interacción comunicativa, por el hecho de que uno de los dialogantes -la madreno logra articular una frase, ni siquiera una palabra, acabadamente. Pero cuando el lector ha entrado a este juego de "complete usted el sentido", divertido por las acrobacias para sortear con éxito los malentendidos y levemente enternecido por la relación entre madre e hijo, que además tiene anclajes de seudo autobiografía del escritor, aparece el monstruo del final: cuando la madre se dispone a hacer pollo al horno, el doméstico y habitual alimento toma vida apenas lo sacan de la bolsa de plástico y asesina a los protagonistas.

b) Si los monstruos aparecen desde el principio, lo que plantean es cómo seguir leyendo, con dubitaciones de género: ¡ah!, estamos en el género fantástico, pero no exactamente, ya que el grotesco cómico ${ }^{4}$ se impone sobre las propias leyes de ese mundo posible creado; entonces, esa libertad absoluta se ejerce a costa de una buena voluntad sin límites del lector (¿un lector masoquista?) que se entrega a lo que sea con tal de ver si hay un límite, divirtiéndose mientras tanto en esta montaña rusa. El lector se familiariza con cierto verosímil de género, por ejemplo, el fantástico para Los fantasmas (1994), en un clima en que el monstruo está naturalizado y construido con un estilo diáfano y correcto. El monstruo es amable, como el Pequeño monje budista (2005), monstruoso por su tamaño: podría entrar en la mochila de los turistas franceses a quienes guía por Corea; o francamente jocoso, como los fantasmas de la novelita citada, quienes conviven con una familia de albañiles chilenos en una obra en construcción en la que hacen toda suerte de burlas, obscenidades, piruetas y son usados como heladera para enfriar el vino. Sin embargo, el humor se torna siniestro a medida que se avanza en la lectura. En el caso de Los fantasmas, mientras el lector pasa página tras página con descripciones banales, sin que "pase nada”, en suspenso, los fantasmas risueños y

\footnotetext{
${ }_{4}^{4}$ Lo minúsculo y lo gigantesco, los contrastes entre lo alto y lo bajo, la corporalidad que rompe los límites de un afuera y un adentro, entre otros motivos, forman parte de la cultura del grotesco, entendiendo por tal no sólo un estilo o una estética como propone Kayser (1964) sino el reenvío a una cultura (Bajtín 1987), donde la desmesura es parte de una política de inversión del orden de la racionalidad como disciplinadora social. Por ejemplo, “los fantasmas heladeras”, como vemos más abajo.
} 
seductores llevan a la joven Patri al suicidio por amor, mediante la invitación a su fiesta -el Gran Reveillon- mientras la familia festeja fin de año. Con El pequeño monje budista, el lector está desprevenido y sólo una relectura le muestra su falta de perspicacia, el abuso de confianza: “icómo no me di cuenta!”, se dice junto a los turistas franceses cuando descubre que el monjecito no es un humano sino que él y el mundo que por él han conocido como Corea, es un "frankenstein" digital en 3D, que se escapó de un programa informático a medio terminar.

c) Por último, nos detenemos en el monstruo que aparece en el desarrollo, una vez bien comenzada la trama. Es el caso de "El gauchito", el feto que toma autonomía una vez que es extraído "a mano" del vientre de su madre y que adquiere poderes sobrehumanos en Yo era una chica moderna (2004). La ubicación in medias res permite presentar no sólo los monstruos sino las monstruosidades que los engendran, la fiesta del monstruo y su nacimiento. Ambientada en un Buenos Aires referencial, el lector se va habituando a lo excepcional: parte de la acción transcurre en la disco "más chica del mundo" y uno de los personajes, Porfiria, es ya un "monstruito" producto de Chernóbil que crece sin parar. Entre estos extremos de lo más chico y lo más alto, medianamente naturalizados (todo el mundo sabe que hay víctimas de las radiaciones de la central nuclear, y una disco muy chica es rara pero no hay ley natural que impida que exista), se va preparando el clímax de violencia nuevamente en manos de dos jóvenes mujeres (como en La prueba, 1992) y su producto directo es "El gauchito". Con una total ausencia de moralización, como en todos los relatos aireanos, el monstruo siembra terror entre inocentes y malvados. No solo "no hay moral", sino que no hay nada de lo políticamente correcto cuando los conspiradores enemigos son rabinos junto al marido de la estrella negra Josephine Baker, benefactores de niños huérfanos. En este caso, el ingreso a la aceptación del monstruo es por la puerta de la vivencia de la violencia extrema e incólume. El lector perdió los límites, es el lector orgiástico, como el de Lamborghini.

Yo era una chica moderna, escrito en primera persona -y debe la consecuente perspectiva interna del personaje narrador, invariable en todo el discurso- ${ }^{5}$ es el relato de las experiencias de dos chicas en una noche de Buenos Aires, un dúo complementario (una especie del doble: no son semejantes sino complementarios), la narradora y Lila. Aburridas, ni felices ni tristes, buscan en el sábado a la noche algo, la vida, y así van de sitio en sitio viviendo aventuras eróticas, criminales, desopilantes, policiales, fantásticas, monstruosas, con las que intentan sobrellevar en estado de borrachera su vida diurna de empleadas en "empresas privatizadas". A pesar de la primera persona, la narradora no reconoce los límites de lo verosímil

5 Este sería el caso que inaugura la serie de relatos de "Mujeres que matan" escritos en primera persona desde la perspectiva de la mujer, que cierra el encadenamiento propuesto por Ludmer (1999). 
en el relato de su propia aventura, como si su ebriedad diegética se continuara en su narración de los acontecimientos, si bien manteniendo siempre el estilo sobrio y transparente de la escritura aireana, con el que compensa al lector de tanto dislate. Se rompen los límites entre sueño y vigilia; en el segundo capítulo, pasadas unas pocas páginas, dice la protagonista narradora: "Me fui a mi casa, que por suerte estaba cerca. Aun así no se como llegué, porque en realidad estaba lejísimo” (23, énfasis mío).

Los términos que he subrayado señalan la ambigüedad de lo narrado, la debilidad de la verosimilización de la trama que progresivamente se va volviendo cada vez más disparatada en ritmo de vertiginosidad creciente hasta el paroxismo de la "fiesta del monstruo", la violencia fantástica desatada.

Las dos amigas, Lila y la narradora, una vez enteradas de que Roberto, el novio de Lila, no se puede casar con ella (a pesar de que hace cinco años que arman metódicamente su ajuar, sus muebles) porque va a tener un hijo con Ada con la que debe casarse por una cuestión de honor, se disponen a hacer justicia, "una justicia risueña y loca” (51). La atrapan en el baño de la disco:

En el baño, entre las dos entradas de la policía realizamos la extracción. Ella gritaba, primero se puso roja como una rosa oscura, después más y más pálida (le bajó la presión), su llanto se hizo angustiado, ya no contra nosotras, ya no destinado a causarnos conmiseración o culpa, sino vuelto hacia ella, como para seguir oyéndose más allá de la muerte. Sentía materialmente la muerte. Nosotras también, pero nosotras además sentíamos la vida.

Sentíamos el sabor del crimen, que nada iguala en la realidad, ni la droga, ni el sexo, ni las privatizaciones. Si este relato cae en manos de chicas como nosotras (que es lo que me propongo y el motivo por el que escribo), aprovecho la oportunidad para recomendarles el crimen como exaltador de la vida. Matar, secuestrar, mutilar, violar, en lo profundo de la noche, en un sótano, en un depósito abandonado, en una casa cuyos habitantes se hayan ido de viaje. La violencia puede ser un problema, lo mismo que los imponderables que puedan presentarse, y sobre todo la resistencia de la víctima. Pero todo se supera, y llega el momento en que queda el crimen puro, la efusión de la sangre, la mirada en blanco que dice "Perdí”, y la risa en rojo que dice "Perdiste"; entonces es como si el crimen empezara: una ola enorme a la que nada puede oponerse. Es una repetición infinita. (53)

Se escuchan ecos arltianos pero desdramatizados por el humor negro. Sigue:

[...] Al fin (fue ella misma la que se lo buscó) quedó cabeza abajo, y nosotras tirando de las piernas, una de cada una, con las aletas de la pelvis apoyadas en los hombros. Hicimos palanca: uno, dos, ¡tres! La vulva se rasgó hacia adelante y hacia atrás, y un chorro de sangre golpeó el techo. La soltamos y antes de que tocara el suelo ya estábamos metiendo las manos hasta el codo en la abertura. [...] 
Nos habría venido bien tener más conocimientos de anatomía.

Los órganos salían envueltos en coágulos, en tubos, resbalosos y blandos. “¿Será esto?” "No, eso debe ser la vesícula.” “¿Yesto? No, quéva a ser. Parece el corazón, aunque ella no tiene.” “¿No será el cerebro?” “iQué asco, qué porquería!” “¿Cómo va a ser el hígado si está cubierto de pelos?” Eran los viejos órganos tradicionales, con los que vivíamos todos, pero en nuestras manos se volvían desconocidos y extraños. Estábamos tan cubiertas de sangre que teníamos que apartar a manotazos las mareas rojas de los ojos.

[...] Ya estábamos a punto de desalentarnos cuando apareció. Era como si hubiera estado jugando a las escondidas. [...] Salimos atropellándonos. Yo lo sostenía en alto con las dos manos. No habíamos pensado cómo esconderlo, ni cómo salir con él a la calle. Ni cómo limpiarnos la sangre que nos cubría de los pies a la cabeza. Esto último tuvo una solución inesperada ni bien hubimos salido del baño. $L a$ placenta estalló, con un plop, y produjo una enorme cantidad de agua cristalina que nos cubrió, dejándonos impecables. Más que eso, fue un baño de belleza. Recordé haber oído decir que la placenta tenía propiedades cosméticas. Nadie antes, como no sea millonaria, se había dado una ducha de placenta. Puedo dar fe de que a Lila y a mí el pelo nos quedó como nunca, sedoso, brillante, armado. (55, énfasis mío)

Con el tono con que se narra el despanzurramiento de un pollo en un programa televisivo de cocina o la búsqueda de un premio en un programa de entretenimientos, se narra el descuartizamiento y hallazgo del feto en el cuerpo de Ada. Mientras el relato se ha ido deslizando del policial al fantástico, la hazaña criminal, con todos los detalles sanguinarios que se relatan en un tiempo de escena, culmina en un inesperado tratamiento de belleza en clave de historieta (“plop”). No se lo priva al lector de ninguna información morbosa, está al tanto de todo lo que hacen las protagonistas con ritmo veloz y al mismo tiempo detenido en el detallismo, propio de una escena vertiginosa en cuanto a la cantidad de acontecimientos, todos de suprema violencia. El distanciamiento desde el que se pasa del horror a la risa está provocado por la incoherencia entre una historia de atrocidades, monstruosa y una escritura juguetona, burlesca, de entretenimiento, de historieta, de publicidad televisiva. Un genial travestimiento humorístico.

No hay castigo de la ley del estado. Logran escabullirse del comisario Cipolletti que no sospecha de ellas, mediante lo que Ludmer caracteriza como propio de los delitos femeninos: la simulación. Además, su crimen perpetrado por amor, por pasión, es un crimen justiciero y con él restauran el equilibrio perdido: Lila allana nuevamente el camino al matrimonio para conformar una familia, célula de la sociedad; se destruye una conspiración gracias a este crimen y a los que sigue perpetrando "El gauchito"; se energiza un alma triste en un cuerpo enfermo con la entrega y transformación del monstruito en un corazón. Familia, patria y salud a salvo. 
De Mao y Lenin, las adolescentes punk y lesbianas de La prueba (1992) que atacan los espacios del capitalismo central (los Pumpers, el supermercado Disco) y matan "consumidores", a las chicas que trabajan en empresas privatizadas y mediante "El gauchito" matan chicos de la calle, turistas extranjeros, ciegan "patovicas" y destruyen conspiradores ${ }^{6}$ han pasado doce años. Las "chicas modernas" también, como las "punks", matan en nombre del amor, pero además, en nombre del matrimonio: el dispendio de monstruosidades es la contracara de la vida ordenada según el eficientismo empresarial de su tarea diurna y sin solución de continuidad se pasa de un mundo al otro como las horas del día, de las actividades diurnas a las nocturnas. Sólo que las monstruosidades de Yo era una chica moderna son más decididamente cómicas y burlescas que las acciones de las chicas punks.

Hay una relación dialógica insoslayable entre las dos novelitas de crímenes de dos jóvenes mujeres. ¿Hay continuidad, hay diferencia? Todas las novelas de Aira pueden ser concebidas como fragmentos de una escritura inacabada. Si bien ambos relatos tienen anclajes referenciales de la época de sus condiciones de producción, el antirrealismo aireano nos orienta para no ceder a la tentación de pensar su escritura con los parámetros del viejo realismo positivista, aquel que encuentra sus temas y sus formas en la Historia. En el artículo ensayístico "El dandi con un solo traje” (2002) Aira se inclina por el realismo que Lukács describió así: "No es la posición del que ve desde afuera la realidad, sino la del que se ha instalado en el núcleo que la genera y habla y actúa desde allí”. Es un realismo (o antirrealismo) siempre nuevo y distinto. La dificultad está en la deshistorización (y en el periodismo) que pretende reemplazar la variedad incontrolable de lo que pasa por las tranquilizantes previsiones de lo que pueda pasar (es más fácil hacer profecías que realismo). El realismo entonces es la sumatoria de la Historia y el Arte, a diferencia de las imágenes actuales de la realidad, en simultáneo, en bruto, sin historia, sin arte, sin tiempo. Por tener la simultaneidad con lo que pasa, nos quedamos sin realismo.

Por otro lado, la narrativa de Aira, como la de Copi según el mismo Aira (1991), es la narración centrada en lo que acontece y no en la información, la narración a lo Heródoto (17), quien cuenta sucesos sin dar mayores explicaciones, señalando sutilmente que desconoce los motivos de las acciones. Las acciones monstruosas de las novelitas de Aira no tienen causa, justificación, más aún, se elude la causa por la ironía paródica de la narrativa "rosa”: los crímenes de las jóvenes mujeres, las atrocidades, son "por amor", lo mismo que otras relaciones monstruosas, como el romance entre un perro y una mosca, o del Papa con una gota de óleo de $L a$

${ }^{6}$ Estos son un dúo de periodistas, uno de izquierda, Melón, otro de derecha, Melamo, que se alternan en los sucesivos gobiernos: en el momento de la diégesis, la izquierda cede el lugar a la derecha, con la estrategia de darle causas políticas al aumento de la criminalidad; también matan a la chica de Chernóbil, a los rabinos, al marido de Josephine Baker. 
Gioconda, como ya vimos, etc. Lo que informa se ambigua, hay entropía, y esa ambigüedad rodea al monstruo: la ambigüedad del humor siniestro, liberador y aterrorizante.

Parto de esta negación de las explicaciones, de esta poética del relato como un puro acontecer, de esta concepción de serie que le produce risa a Foucault (56), con un "malestar cierto y difícil de vencer" a partir de la lectura de la clasificación de los animales según cierta enciclopedia china en el texto de Borges, "El idioma analítico de John Wilkins". Lo monstruoso es la serie, lo que separa uno de otro ser, ese espacio en blanco para las posibilidades “otras”, las imposibles de pensar, la continuidad imposible; lo monstruoso, inquietante y risible no es la proximidad de las cosas sin relación, sino el espacio común, el sitio en ruinas. Esa es la relación entre las secuencias de los relatos de Aira, es parte de su poética particular. Ahora bien, como su obra juega permanentemente con la insignificancia, con materias "bajas", estructuras endebles, hay en casi todas las narraciones de Aira (además de sus ensayos y sus textos seudo autobiográficos) un lugar donde el texto se describe a sí mismo, pequeñas poéticas cifradas, con las que compensa tanto "no sentido", pero en el borde de la broma, en esa arista basculante en que todo puede ser o no "en serio", como la enigmática “sonrisa seria” que aparece en gran parte de sus personajes novelescos. Se trata de una hermenéutica de superficie, como la carta robada del relato de Poe. Como en ese relato, el criminal, o sea el escritor, no esconde su cifra sino que la muestra donde no se la espera. Ese lugar, por ejemplo, es la voz de Mao, joven lesbiana seudo punk, ${ }^{7}$ una de las tres protagonistas de La prueba. Después de relatar magníficamente un episodio de la historia de "Sergio Vicio" para Marcia, a quien intenta seducir (fragmento en que esta narradora metadiegética despliega las artes de la narración pura de sucesos, como el narrador básico), y mediante una broma escabullirse de la supervisora del Pumper (haciéndole creer algo que la deja desubicada por la duda), Mao explicita: "Ese mundo de explicaciones en que vivís es el error” (62). Listo, ahí está condensada la poética que se desplegará en la pura acción, sin explicación, como prueba de amor. Relato impecable, una situación violenta que rompe el clímax de "calidad" intelectual, broma para permanecer en el sistema que se destruye desde adentro (el Pumper), acción desorbitada sin explicación (el mundo real vs. la explicación), incerteza (no es el mundo al revés, simétrico, en espejo), son las palabras claves de esta mini poética. Un año después (aunque antes de la publicación de La prueba), en un texto ¿casualmente? sinónimo, "El test. Una defensa de Emeterio Cerro”, Aira concluye: “¿Quién dijo que la literatura era una profesión para bien pensantes?” (1990: 41).

\footnotetext{
Se podría jugar con esta caracterización como representación de esta escritura: la de la inmadurez joven que permite el juego y el derroche, la relación de la literatura con la literatura misma y la transgresión permanente con el corrimiento de los clisés identitarios.
} 
Es la broma Aira; en el texto homónimo (1997) dice:

Está la escena clásica, en el andén del subte, cuando viene el tren a toda velocidad por su tubo hondo y espantoso... la máquina de picar carne... bastaría un pequeño empujón en el momento justo y ahí se va mi futuro... yo apenas si lo sentiría, un vértigo super comprimido, después saldría en los diarios, mis hijos huérfanos, mis libros sin terminar: lo definitivo. [...] alguien se me acerca desde atrás (yo estoy pensando en cualquier otra cosa) y me toma por los brazos, un poco abajo de los hombros, con el vigor sobrehumano que le da mi abandono, y me empuja y me retiene al mismo tiempo, como para significar el crimen horrendo pero no cometerlo... iporque es una broma! (45-46)

Lo que la hace una broma, precisamente, es la posibilidad remotísima, pero que tiene que existir y en ese mismo momento, de que sea en serio. Lo extraño es que la irritación que produce una broma de tan mal gusto se disipa si es en serio, o sea, si es un asesinato, si es real.

Sólo con la broma se puede creer por un instante en otra cosa y no pasar a otra cosa, poder continuar. Sobre esos niveles, lo que es broma y el segundo en que puede no serlo y ser la realidad, se da el pasaje de lo monstruoso a lo humano y viceversa. Sobre la equivalencia entre chiste y realidad se edifica la obra de Aira: ambos no pueden explicarse, cuando se los explica dejan de ser lo que son, chiste o realidad. El malentendido se corresponde con la broma: se hace creer algo por un instante, se comunica otra cosa, y ese malentendido que es la broma deja huella, una huella transparente.

Aesta breve paráfrasis de La broma se podría jugar a trasladarla a su producción como una mini poética que de alguna manera instale balizas para leer: ese entrever lo real, que sería "morir aplastado" y tener no obstante al segundo siguiente la conciencia de ser un sobreviviente, se debe a que se lo está contando, a que se escribe un relato (se puede contar el cuento). Se escribe ese pasaje entre lo humano y lo monstruoso con la única forma que lo permite, en forma de broma. La broma permite la oscilación, un instante separa un nivel de realidad del otro, de lo real de la realidad con relación a un simulacro bromista sobre ella. Esa realidad es la suspensión del juicio, la incerteza. Sus efectos son la carcajada e irritación: se creyó una cosa en serio (aunque sea un asesinato) y resultó broma. Y, como lo real de la realidad, como el chiste, no soporta la explicación: con ella desaparece. No hay explicación, no hay cadena causal sino series de bromas, bromas diferentes, que desatan creencias momentáneas, fugaces, efímeras, sobre lo otro, lo monstruoso por informe ("ser una bolsa reventada de vísceras y huesos rotos"), único e irrepetible, de la realidad.

Ariesgo de ser víctimas de la misma broma que se denuncia, seguimos haciendo una lectura cifrada. Ahora toca ver la broma Aira, la operación cultural como una 
operación bromista, broma al lector individual, broma a la academia, al periodismo cultural. Y ver en esa broma, precisamente, la escritura monstruosa, no sólola escritura sobre monstruos y monstruosidades. Monstruosa por su singularidad extrema (el monstruo es un individuo que no se reproduce) y extraña: un "monstrum" que se exhibe más allá de la norma.

Esa escritura monstruosa lo es también por lo infinita, más allá del texto. Aira dice a propósito de la escritura de Copi, en fragmentos que pueden autorreferenciarse:

El texto ya escrito, con el que se enfrenta el lector, es una extensión dada. Pero dentro de esa extensión persisten las tensiones que la hacen incierta: el autor puede tomar cualquier decisión en cualquier momento, y cuanto más libre haya sido para tomarla, mayor será la adhesión del lector a esa ecuación de lo finito del texto y de lo infinito del escritor. Dada una cantidad infinita de hechos narrados, el relato podría llegar hasta el lector. Esa es la función del infinito en la literatura. (36-37)

Esto es lo que anuda las dos novelas citadas: la mini poética que describe en La prueba, en boca de Mao, es la que expande en Yo era una chica moderna. Esta es la línea de la continuidad, mientras que la del cambio es la que ya apuntamos: la radicalización de las rupturas del verosímil, los monstruos y monstruosidades imposibles de pensar, escritura monstruosa que pide un lector ídem, por infinita, por bromista. La expansión de historias se construye con las historias suspendidas, abandonadas: un continuum de segmentos sin causa, sin secuencia. Su ya famosa propuesta de "huida hacia delante" para tapar la falta, lo "mal hecho", desata la monstruosidad, allíson intercambiables lo más pequeño(los detalles) y lo más grande (la monstruosidad); por eso el “feto”, las niñas, las jóvenes, o sea los más pequeños o débiles, hacen las mayores monstruosidades. Estas historias dejan lugar para la expansión ad infinitum de lo porvenir, se abren a lo sideral y con esto empiezan a parecerse a la realidad. Por eso todas tienen un final abrupto y fechado.

Intentamos, entonces, algunas reflexiones por el arte y por la historia. Esta estética de lo peor (Pardo, 1998), el fundamento de la desestetización de la cultura, está en las consignas de Benjamin, quien en 1933, previendo la guerra y en medio de la crisis económica, escribió: "Hemos de prepararnos para sobrevivir a la cultura” (citado en Pardo, 62). Esta consigna, de múltiples interpretaciones, puede ser comprendida si se la compara con una fórmula de Hitler, pronunciada en la "sesión sobre la cultura" del Congreso del partido del Reich en Núremberg, 1935: "Ningún pueblo sobrevive a los documentos de su propia cultura". Frente a esa promesa de estetización la voluntad de sobrevivir a la cultura a la que apela Benjamin remite a una cierta "desestetización" expresada en "Fiat mundus, pereat ars", consigna que es hija de la conciencia de que "todo documento de cultura, en 
la medida en que se erige sobre la sangre, la injusticia y el sufrimiento, es también un documento de barbarie”. Dice Pardo:

El Exterminador, puesto a recubrir su maldad con los atributos de la belleza, rechazará siempre los de la repugnancia. Ahí están, pues, los motivos del cíclico renacimiento de lo repulsivo, tan éticamente intachables como, quizá, estéticamente estériles [...] No es por tanto otro canon lo que se oculta tras ellos, como tampoco tras la música atonal, o tras la pintura no figurativa, como podía pensarse en los tiempos de las jóvenes vanguardias históricas, sino una deliberada falta de voluntad canónica como barrera que ha de impedir que la obra de arte represente alguna forma de autoconciencia de un "espíritu” colectivo, pues tras toda melodía susceptible de ser coreada se adivina aún el eco demasiado próximo de las políticas culturales totalitarias. (62)

Frente a ellas, lo propio de los monstruos de hoy en día, en especial de los monstruos que dan risa, es la particular operación cultural por la que retoman la tradición; el objetivo no es el eclipse de los pueblos propio de la globalización sino una reescritura de los tópicos nacionales: Moreira, los indios, los gauchos, los viajeros extranjeros, las villas miseria, los jóvenes porteños, los niños peronistas, los profesores de literatura. "La refalosa” de Ascasubi provee la matriz para la fiesta del monstruo. De ella dice Ludmer (1988): “Lo monstruoso es el desplazamiento a lo humano de la matanza de animales”. Tal cual el descuartizamiento leído más arriba. Pero la radical inversión está en la perspectiva y la voz desde la que se lo narra. Se narra desde el monstruo, no desde quien acusa las monstruosidades. ${ }^{8} \mathrm{Y}$ además, el monstruo no es un rudo mazorquero sino dos chicas modernas que de día trabajan en empresas privatizadas y de noche van a las discos, una de ellas lo que más quiere en la vida es casarse y por eso descuartizan, por amor. Lo mismo que en La prueba. Y de paso, el pelo les queda sedoso y con cuerpo, no olvidarse. La energía sobrenatural que despliega “El gauchito” (su nombre reenvía nuevamente a la tradición de "La refalosa”) produce destrucción a mansalva. Tanto carboniza a un chico de la calle:

Le lanzó por el pitín un líquido blanco que lo cubrió de pies a cabeza. Seguramente era una especie de ácido porque vimos consumirse toda la carne del chico: el esqueleto, negro y quebradizo como hecho de minas de lápiz, se tambaleó y después salió corriendo. (64)

\footnotetext{
8 En otro lugar vimos como en "Todo por dos pesos", el programa televisivo protagonizado por Capuzoto y Alberti, en el episodio de "Irma Jusid", se ríen de las monstruosidades que le pueden hacer a un estúpido y desprevenido chico bien pensante. O sea, desde la misma perspectiva que "La refalosa” se invierte su valoración por la parodia.
} 
como con la misma energía y esta estética travestida de dibujito animado, destruye a los conspiradores, ciega a los patovicas, y se entrega totalmente y para siempre, como corazón de un chico con una vida muy triste que con ese gesto, de suprema solidaridad, renace a una vida feliz.

Estos monstruos impugnan lo bello, como todo monstruo, es decir lo bello convencional, pero a su vez, en tanto monstruos que dan risa, impugnan también la puja por la moda que es propia de la estética, ya sea la moda por lo bello que es la que triunfa en lo cotidiano o la moda por mostrar lo más feo, bajo y terrible de la miseria de la vida cotidiana de muchos argentinos con que los medios masivos, sobre todo la televisión, le ganan al arte en tanto la muestran espectacularizándola, poniendo distancia. Como la representación es siempre más tranquilizadora que la vivencia, que la experiencia, las discursividades que estamos presentando no sólo muestran monstruos, son ellas mismas monstruosas, el lector deviene monstruo. Pero por el humor, las atrocidades se perciben desde el ojo que miniaturiza, desde el telescopio invertido: para poder dar cuenta de lo más cercano en el tiempo y el espacio, se busca el lugar del etnólogo, o sea el lugar de distancia y no obstante, de la participación. Esto se logra invirtiendo la óptica para que el niño, el menor ("El gauchito" y también el lector que deviene niño disfrutando de escenas como de "dibujos animados", y las jóvenes chicas modernas) no se deje apabullar por los gigantes y los vea lejanos y miniaturizados, como un "guignol truculento" (La prueba 69). La miniaturización y la incongruencia de contrarios construyen un grotesco de raíces en la cultura humorística popular: "El gauchito” como feto está en el borde, monstruo ambiguo como dijimos, es al mismo tiempo, nacimiento y muerte. ${ }^{9}$ Por el escenario de la calle Florida de noche pasan los turistas extranjeros, los patovicas cegados, las estatuas vivientes y las familias que huyen de la fiebre amarilla hacia el norte: barroco, grotesco, absurdo, teatro risible para las monstruosidades:

El gauchito se puso como loco al ver por primera vez las estatuas vivientes. La impresión lo achataba y se ponía cóncavo como un wok. Soltaba un grito de asombro. Debía de producir una especie de vacío, porque las estatuas vivientes salían proyectadas hacia atrás a velocidad fantástica, y chocaban contra grupos de turistas sonámbulos, desparramándolos por todos lados como en el bowling. La risa que le producía esta gracia era contagiosa. [...] Los turistas volaban y caían de cabeza. Los mendigos, niños y adultos, se precipitaban a robarles la billetera... (68-69)

\footnotetext{
9 La supervivencia del feto como monstruo se ve ahora en discursos posteriores a este, como en la historieta "Mamá Pierri", de Langer, en que el feto viola y martiriza a la representante de la alta burguesía conservadora de la derecha nacionalista argentina.
} 
Son monstruos libertarios, humorísticos, que permiten disfrutar del desmadre con la ingenuidad de un niño, o de chicas modernas. Un monstruo del borde, no es netamente lo feo o desestetizado benjaminiano, es cruel pero también gracioso y solidario. Uno se ríe con el monstruo porque los personajes, como en toda la narrativa aireana, son planos, sin profundidad, casi como marionetas o como dibujos animados, movidos por impulsos que parecen exteriores, por acciones y reacciones que se disparan en cualquier dirección, según las circunstancias, siempre anárquicas. Y los monstruos, objetos y sujetos de la violencia extrema, son al mismo tiempo su caricatura: Porfiria, la víctima de Chernóbil que crece sin parar, se convierte en un filamento infinito que se pierde en la profundidad sideral y su amiga, víctima de "las chicas modernas", es un cadáver manipulado como mannequin; son cuerpos desnaturalizados en su dimensión humana para formar parte del grotesco humorístico. Arte miniaturista, ilustra la teoría bergsoniana del humor, basada en la risa distanciada que produce la percepción de automatismos; en Yo era una chica moderna la escena del desmadre en la calle Florida, descripta como "un gran guignol truculento" (69), oficia, nuevamente, de cifra hermenéutica de esta poética. ${ }^{10}$ Es un monstruo inasimilable porque es el otro de la seriedad, de la causalidad, del orden. Gasto inútil y goce. El dispendio de las monstruosidades como la contracara de la vida diurna de las chicas empleadas en las empresas privatizadas rompe la solución de continuidad, nuevamente el continuo aireano evidencia la incongruencia que produce la risa: en el mismo enunciado se pasa de la apología de la monstruosidad de la suprema violencia al discurso publicitario sobre la belleza de los cabellos. Está el fantasma del deseo sin represión, en el mundo ordenado del capitalismo neoliberal. No hay desdoblamiento del sujeto, no tiene que elegir entre desembarazarse prestamente de la moral productivista o asumir irrevocablemente el destino de mero simulacro (Klossowski, 1998); no hay renunciamiento al deseo violento en pro de su sublimación en el orden civilizatorio sino tránsito de una a otra dimensión con la conciencia indivisa. Es una respuesta no habitual a la ley de la opción, de la dualidad, que produce placer como todo derribamiento de límites, pero es un placer incómodo, una risa militante.

\footnotetext{
${ }^{10}$ No sólo los personajes son planos, también lo es la representación del espacio, como las viviendas
} de papel de los indios de Ema la cautiva que recuerdan a la escenografía del filme Dogville. 
BIBLIOGRAFÍA

Abraham, Tomás. Fricciones. Buenos Aires: Sudamericana, 2004.

Aira, César. “El test. Una defensa de Emeterio Cerro”. Revista Babel III/18 (agosto, 1990).

Copi. Rosario: Viterbo, 1991.

Embalse. Buenos Aires: Emecé, 1992.

La prueba. Buenos Aires: Grupo Editorial Latinoamericano, 1992.

Madre e hijo (Una pieza en un acto). Rosario: Bajo la Luna Nueva, 1993. Los fantasmas. Caracas: Fondo Editorial Fundarte, 1994.

Taxol, precedido de Duchamp en México y La broma. Buenos Aires: Simurg, 1997.

El congreso de literatura. Buenos Aires: Ediciones Tusquets, 1999.

"El dandi con un solo traje". Babelia (suplemento de El País, 31-012002).

Yo era una chica moderna. Buenos Aires: Interzona, 2004.

El pequeño monje budista. Buenos Aires: Mansalva, 2005.

Bajtín, Mijail. La cultura popular en la Edad Media y en el Renacimiento. Madrid: Alianza, 1987.

Flores, Ana B. "La incomodidad que hace reír. César Aira y “Todo por dos pesos”.

2. La Argentina humorística. Cultura y discurso en el 2000. Córdoba: Ferreyra Editor, 2003. 35-45.

Foucault, Michel. Las palabras y las cosas. México: Siglo XXI, 1987.

Kayser, Wolfgang. Lo grotesco. Madrid: Gredos, 1964.

Klossowski, Pierre. La moneda viviente. Trad. y notas de Axel Gasquet. Córdoba: Alción, 1998.

Ludmer, Josefina. El género gauchesco. Un tratado sobre la patria. Buenos Aires: Sudamericana, 1988.

El cuerpo del delito. Un manual. Buenos Aires: Ed. Perfil, 1999.

Moreno, María. "La flor de mi secreto”. Radar libros (16-07-06).

Pardo, José Luis. "La estética de lo peor”. Revista de Occidente 201 (Madrid, febrero 1998).

Tabarovsky, Damián. Literatura de izquierda. Rosario: Beatriz Viterbo, 2004. 